\title{
Extended performer: evolución y cambio de rol del intérprete musical: hacia una música expandida*
}

EXTENDED PERFORMER: EVOLUTION AND CHANGE OF THE MUSICAL PERFORMER'S ROLE: TOWARDS AN EXPANDED MUSIC

EXTENDED PERFORMER: EVOLUÇÃO E MUDANÇA DE ROL DO INTÉRPRETE MUSICAL: RUMO A UMA MÚSICA EXPANDIDA

\section{Haize Lizarazu González**}

Cuadernos de Música, Artes Visuales y Artes Escénicas

/ Volumen 14 - Número 1 / Enero - Junio de 2019

/ ISSN 1794-6670 / Bogotá, D.C., Colombia / pp. 115-127

Fecha de recepción: 30 de abril de 2018

Fecha de aceptación: 10 de octubre de 2018

Disponible en línea: 28 de diciembre de 2018

doi 10.11144/javeriana.mavae14-1.epey

* Artículo de reflexión. Es parte del proceso de reflexión y análisis de mi profesión como intérprete y de mi tesis de fin de máster en arte sonoro en la Universitat de Barcelona.

* Grado superior en Música en la Escola Superior de Música de Catalunya, magíster especializado en Música Contemporánea por Hochschule für Musik Basel y magíster en Arte Sonoro por la Universidad de Barcelona. ORCID: 0000-0001-7444-2299

\section{Cómo citar:}

Lizarazu González, Haize. 2018. "Extended performer: evolución y cambio de rol del intérprete musical: hacia una música expandida". Cuadernos de Música, Artes Visuales y Artes Escénicas 14 (1): 115-127. http://doi.org/10.11144/javeriana.mavae14-1.epey 


\section{Resumen}

Este artículo pretende ser una aproximación analítico-reflexiva de la función del intérprete musical en el campo de la música contemporánea y experimental hoy en día. Desde sus orígenes y desde el momento en que el intérprete se desligó de la figura del compositor, sus funciones y maneras de abordar la música, su estudio e interpretación han ido variando. Estas variaciones, sin embargo, siguen estrechamente vinculadas a los cambios de corrientes y visiones compositivas y de cómo estas definen los conceptos de idea musical, proceso creativo o resultado sonoro. El término utilizado para describir a este nuevo tipo de intérprete, extended performer, se refiere a cómo esta función se ha extendido, expandido, más allá de los límites de una práctica instrumental o performativa. Perfilando los orígenes históricos del intérprete musical y pasando por los cambios de paradigma que sucedieron durante el siglo $X X$ con las diferentes corrientes vanguardistas y con nombres propios, tales como John Cage o Pierre Boulez, llegaremos al citado extended performer actual, ejemplificando esta nueva figura a través de movimientos compositivos actuales, la importancia de la digitalización en el arte y cómo esta ha planteado una nueva relación entre el intérprete y su instrumento.

Palabras clave: intérprete; performer, música experimental; música contemporánea; Fluxus; Neuer Konzeptualismus

\section{Abstract}

This article aims to be an analytical-reflective approach to the role of the musical interpreter in the field of contemporary and experimental music today. From its origins and from the moment in which the interpreter was separated from the figure of the composer, their functions and ways of approaching music, their study and interpretation have been changing. These variations, however, remain closely linked to the changes of currents and compositional visions and how they define the concepts of musical idea, creative process or sound result. The term used to describe this new type of performer, extended performer, refers to how this function has been extended, expanded, beyond the limits of an instrumental or performative practice. Profiling the historical origins of the musical performer and going through the paradigm changes that took place during the 20th century with the different avant-garde currents and with proper names, such as John Cage or Pierre Boulez, we will reach the aforementioned extended performer of the present, exemplifying this new figure through current compositional movements, the importance of digitization in art and how it has raised a new relationship between the performer and their instrument.

Keywords: performer, experimental music; contemporary music; Fluxus; Neuer Konzeptualismus

\section{Resumo}

Este artigo pretende ser uma aproximação analítica-reflexiva da função do intérprete musical no campo da música contemporânea e experimental hoje em dia. Desde suas origens e desde o momento em que o intérprete se desligou da figura do compositor, suas funções e maneiras de abordar a música, seu estudo e interpretação vêm variando. Estas variações, contudo, continuam estreitamente vinculadas às mudanças de correntes e visões compositivas e de como estas definem os conceitos de ideia musical, processo criativo ou resultado sonoro. O termo utilizado para descrever este novo tipo de intérprete, extended performer, se refere à maneira como esta função tem se estendido, expandido, mais além dos limites de uma prática instrumental ou performativa. Perfilando as origens históricas do intérprete musical e passando pelas mudanças de paradigma sucedidas durante o século XX com as diferentes correntes vanguardistas e com nomes próprios, tais como John Cage ou Pierre Boulez, chegaremos ao citado extended performer atual, exemplificando esta nova figura a través de movimentos compositivos atuais, a importância da digitalização na arte e como esta tem abordado uma nova relação entre a intérprete e seu instrumento.

Palavras-chave: intérprete; performer, música experimental; música contemporânea; Fluxus; Neuer Konzeptualismu 


\section{EL INTÉRPRETE MUSICAL: DEFINICIÓN Y APROXIMACIÓN HISTÓRICA DE SU ORIGEN}

Empecemos por el principio: el intérprete musical es aquella persona que interpreta una obra musical. Simple (y un tanto redundante) en apariencia. Pero ¿qué es interpretar? Aquí nos encontramos con un término que tiene múltiples definiciones y que ha sido objeto de estudio en la hermenéutica; ese arte de explicar y transmitir por el esfuerzo propio de la interpretación aquello que no es comprensible de un modo inmediato (Gadamer 1996, 57).

Sobre el significado de interpretar podríamos remitirnos a las extensas reflexiones que Gadamer ha hecho al respecto y comenzar por la propia palabra alemana a la que se traduce, deuten, que significa señalar en una dirección. Lo importante es que todo interpretar no señala hacia un objetivo, sino solo en una dirección, es decir, hacia un espacio abierto que puede rellenarse de modos diversos. Deducimos, pues, que interpretar no es dar una respuesta concreta, ya que, precisamente, solo puede interpretarse aquello cuyo sentido no esté establecido, aqueIlo, por tanto, que sea ambiguo, "multívoco" (1996, 75-76). Deberíamos, asimismo, mencionar términos como "traducir", "ejecutar" o "explicar" ("Interpretar" 2014). Si nos referimos a la traducción de textos escritos, en muchos casos, esta acción lleva implícita casi siempre una interpretación, puesto que todos los idiomas poseen formas de expresión propias e intraducibles literalmente, como consecuencia de su evolución etimológica y contexto histórico-cultural. Cuando hablamos del término "explicar", se entiende que toda explicación tiene su naturaleza en la incomprensión. Es decir, todo hecho, acción, texto u obra que no sea del todo comprendida a priori va a necesitar de una explicación. Dependiendo de la fuente u origen emisor de la cual venga dicha explicación, podrá alterar el sentido o mensaje que llegue al receptor (dado su grado de subjetividad y el empleo de las palabras/sonidos/imágenes de manera personal) y, por consiguiente, quedará siempre abierto a la interpretación. Pero, además, cuando hablamos de arte (o de expresiones artísticas de cualquier tipo), asumimos que la multiplicidad de significados es la principal característica por la que la obra de arte necesita una interpretación (y no solo por su incomprensión). En la música, es más que evidente la necesidad de la interpretación para poder materializar el mensaje del autor; la idea musical que este pretende imprimir en la partitura. Debido a su naturaleza inmaterial y utilización de signos "no lingüísticos" para su representación, la codependencia entre compositor e intérprete es innegable.

Volviendo a los términos antes expuestos, vemos que algunos autores utilizan la palabra "ejecutar" para referirse al intérprete musical. Así lo vemos, por ejemplo, en la categorización que hace Stravinsky a la hora de referirse, según su criterio, al buen intérprete:

La noción de ejecución implica la estricta realización de una voluntad explícita que se agota en lo que ella misma ordena. La noción de interpretación sobreentiende los límites que están impuestos al ejecutante, [...] que termina en la transmisión de la música al oyente. [...] Todo intérprete es al mismo tiempo y necesariamente un ejecutante. La recíproca no es cierta. (2006, 110-111)

Haciendo un paralelismo con los términos antes expuestos y referidos, principalmente, a los textos escritos, podría indicarse que el ejecutante del que Stravinsky habla sería aquel que traduce el material que tiene ante él y el intérprete, además de dicha traducción, muestra, hace visible y tiñe de cierta subjetividad (fundamentada) el mensaje del texto 
musical. Es en el segundo tipo de músico en el que encontramos la función hermenéutica del intérprete. Esa subjetividad fundamentada es la que marca la diferencia, existe antes que el sonido mismo. Es un trabajo previo a la emisión del mensaje musical y por defecto previo a su recepción.

Podríamos señalar que existen tres tipos de conceptos de interpretación en lo que al plano hermenéutico se refiere: comprensión de relaciones internas del texto, aproximación al contenido estético e interpretación referencial o semiótica. En el primero de los casos, hablamos sobre la interpretación en el texto de las relaciones estructurales como generadoras de sentido musical. En el segundo tipo, habría que tener en cuenta las explicaciones de hechos inmanentes de las obras por medio de acontecimientos externos a ellas mismas, como datos biográficos o contextos histórico-culturales de la obra y del autor. Por último, al referirnos a la interpretación referencial o semiótica, trasladamos el foco directamente a la historiografía de la música y a la biografía musical, en las que se desarrollan los objetos de la historia de la música como hechos y problemas necesitados de explicación (Danuser 2016, 22).

Una vez finalizado el trabajo previo al sonido, tal y como hemos expuesto, necesitaríamos uno posterior que "materialice" todas las reflexiones y conclusiones derivados de la hermenéutica y los transforme en resultado sonoro. Necesitamos la segunda función del intérprete para que la idea musical, que comienza en un estado previo al sonido en la mente del autor, culmine en su recepción por un público oyente. Nos referimos a la función performativa. Aquí podríamos remitirnos a Hegel (1985), que distinguía entre dos tipos de interpretación: una que se sumerge en la obra y la reproduce y otra que, aprovechando la libertad que el compositor deja al intérprete, explota la expresión (Pardo 1999, 137). La primera pide una interpretación más objetiva, demanda que la música hable por sí misma y se perciba sin la intervención del sujeto que interpreta. La segunda permite que el intérprete forme parte de la música, es más, lo exige, dejando márgenes libres para insertar creatividad a la obra. Es decir, el proceso creativo no es completo del todo hasta que no haya sido interpretado.

En definitiva, podemos ver que las opiniones de Stravinsky y de Hegel no difieren tanto en lo fundamental. Las dos tipologías de intérprete, tanto en lo referente a la hermenéutica como a lo performativo, trazan su línea divisoria en la implicación del intérprete sobre la obra (objetividad versus subjetividad).

Estos tipos de diferenciación y funciones que se atribuyen al intérprete musical han estado vigentes desde los orígenes de los más afamados músicos, tales como Clara Schumann, Franz Liszt o el célebre Glenn Gould. El músico que interpreta obras de épocas pasadas (y propias) surgió con ellos como una opción de oficio, de carrera musical. El origen de la musicología y la evolución del pensamiento estético han favorecido, además, que este oficio tenga nombre propio y esté más que fundamentado a todos los niveles como una disciplina autónoma e independiente. Sin embargo, lo que un día fue una opción, a partir del siglo XX, y gracias a la proliferación de diferentes autores y nuevos movimientos artísticos y musicales, la interpretación se presenta como una necesidad y el intérprete, en consecuencia, como alguien indispensable para el desarrollo de la música como disciplina artística. 


\section{CAMBIO DE PARADIGMA}

\section{EL SIGLO XX Y LAS VANGUARDIAS HISTÓRICAS}

Aunque es difícil determinar una fecha concreta, a partir del siglo XIX, la figura del músico comenzó a dividirse y a diferenciar entre compositor e intérprete. Esta desambiguación, vigente aún hoy en día, es la causante de que ambas disciplinas estén irremediablemente ligadas. Sin embargo, la división de roles no fue equitativa. La interpretación musical se gestó como una disciplina subordinada a la composición, ya que la música académica occidental eleva claramente la idea musical, materializada posteriormente en obra por el autor, al estatus más elevado en la línea jerárquica. Esta forma de pensamiento está históricamente fundamentada y aceptada, ya, incluso, desde la separación existente entre música teórica y práctica en la Edad Media. No es de extrañar, entonces, que, a partir del siglo XX, los mayores cambios estéticos y conceptuales referentes a la interpretación sean consecuencia de la proliferación de los múltiples estilos compositivos que nacieron de la mano de algunos nombres propios de la composición.

Actualmente, es ya una convención señalar a Arnold Schönberg como el autor del mayor cambio de contenido musical en la historia (hasta esa fecha, al menos). La ruptura con el sistema tonal a principios del siglo XX (y el nacimiento así del serialismo dodecafónico y el atonalismo) marcan un antes y un después en la historia de la música, y asientan las bases de las posteriores vanguardias. Podría afirmarse que, a partir de Schönberg, se delimita el inicio de lo que posteriormente los teóricos han llamado música (clásica) contemporánea.

Sin embargo, y a pesar de la gran revolución que supuso el abandono de la jerarquía tonal, el serialismo de la segunda escuela de Viena seguía anclado en la forma musical romántica. La ruptura fue en lo referente al contenido musical, no al continente. Esta matización es muy importante en lo que al campo de la interpretación se refiere, debido a que la manera de abordar estas obras para un intérprete no varía tanto en comparación con otras obras de autores anteriores a ellos. Cambian las ordenaciones de sonidos, estructuras armónicas y resultados sonoros, pero la estructura formal, la tímbrica, la relación de tensiones y distensiones, la rítmica, la métrica, la agógica, etc., en definitiva, todas aquellas relaciones internas del texto musical a las que se somete el proceso hermenéutico antes expuesto siguen -a grandes rasgos - el mismo patrón que en épocas anteriores.

Fue más adelante, con la aparición de corrientes como el uso de la forma abierta, la música electroacústica, la aleatoriedad, la indeterminación, el uso del azar, Fluxus o Musik Theater, cuando el intérprete toma especial protagonismo y se torna indispensable como parte de la idea musical. Los límites de la estructura musical que veíamos en los vieneses se difuminan hasta desaparecer gracias a nombres como Pierre Boulez, Karlheinz Stockhausen, John Cage o Mauricio Kagel.

A mediados del siglo $X X$, tras acabar el periodo sociopolítico más convulso de la historia, el mundo musical estaba en plena ebullición creativa. Existía en aquella época un tridente de nombres propios que definirían las corrientes más relevantes de la música contemporánea de la época y de los años venideros: Pierre Boulez, Karlheinz Stockhausen y John Cage. El trabajo de todos ellos fue muy importante para redefinir el rol del intérprete en la música. Los tres autores empiezan a replantearse qué es una obra musical 
y cómo puede abordarse para que sea autónoma, para que dos interpretaciones no puedan nunca sonar iguales. A causa de esta pregunta, empieza a tomar peso el concepto de aleatoriedad como parte del proceso creativo de una obra musical. La aleatoriedad va a ser la consecuencia de que el compositor asuma un carácter "relativo", pero pronto va a haber dos concepciones muy diferentes de esa posición relativa: la europea (Boulez) y la americana (Cage). A pesar de partir de un punto común (el concepto de aleatoriedad), ambos compositores acaban en puntos opuestos del camino si hablamos de la introducción del azar. Boulez habla de eliminar la intencionalidad estética del compositor en la forma de la obra (en la obra misma); Cage quiere eliminar, además, la intencionalidad constructiva del compositor. Stockhausen encontrará un camino intermedio entre ambos fijando su propia hoja de ruta (Fernández 1985, 30).

Con la Tercera Sonata para piano (1957), Boulez abre la puerta a la forma abierta o "forma flexible" al escribir una obra que tenía diferentes "bloques" estructurales (formantes), que el intérprete podía reordenar para crear en cada concierto una obra diferente si lo deseaba. Casi a la vez, Stockhausen presenta su Klavierstück XI, haciendo uso también de componentes aleatorios a la hora de componer la obra. Pero para entonces Cage ya se había rendido a la aleatoriedad total haciéndolo parte esencial de su modus operandi.

Unos años antes, en 1949, Cage escribe Lecture on Nothing, obra clave para entender el pensamiento del compositor y para ejemplificar la visión que tiene acerca de la forma y el contenido, que, como veremos en algunas obras posteriores, son conceptos que acaban desapareciendo de su discurso. O mejor dicho, forma y contenido devienen lo mismo (Pardo 2014, 78). Cage comenzó su viaje por el discurrir de la nada. Quería despojarse de todo prejuicio estético, formal, de contenido, de material, etc., para poder discurrir sobre la nada. Como él mismo escribía: "I have nothing to say and I am saying it" (1973, 109). Cage acepta la nada como el todo, separación como posibilidad de unión, y así rechaza el discurso dualista (sonido-silencio) que había prevalecido hasta la época. De este modo, dará paso a la entrada del azar y abrirá la puerta a la interpretación de una forma desconocida hasta entonces (Pardo 2014, 71).

Al aceptar el caos y el azar como parte de su método compositivo, Cage rechaza la obra musical tal y como se concebía, y lo más representativo de todo, rompe con ello la jerarquía que se imponía entre el autor y el intérprete. La idea musical deja de ser la verdad absoluta y la intencionalidad del compositor desaparece en pro de la interpretación en el tiempo presente. El proceso de creación de una obra musical deja de ser vertical (estando la idea musical del autor en la cima de la pirámide) para pasar a ser horizontal. Todo se iguala y el intérprete pasa a ser una suerte de autor al mismo tiempo, ya que las posibilidades de crear una obra nueva en cada interpretación son casi infinitas.

Esta nueva manera de abordar el proceso creativo y artístico fue una de las más fuertes influencias para crear, unos años después el movimiento Fluxus. Este grupo de artistas desplegó una propuesta que ponía el énfasis en el proceso de interpretación o performance de las piezas, y renunciaba así al postulado tradicional, según el cual el objetivo y resultado de la actividad creativa debía ser la confección de una obra acabada en sí misma (Rivière 2011, 422). Este arte de acción hacía hincapié, entonces, en lo efímero de la representación artística y se plantea como un acto inconcluso y despojado de esa aura que se le otorgaba al "objeto" musical. Con Fluxus nacieron la performance y el happening, expresiones artísticas que convertían al autor en intérprete (performer), y viceversa. 
A partir de aquí, ya no podemos seguir hablando de aquella figura de intérprete musical, de instrumentista o de ejecutante. Todas las líneas que definían antes este término se han difuminado e incluso extinguido. Podríamos decir que ha mutado, y a partir de estos movimientos, el rol del performer se convierte en parte activa y necesaria del proceso creativo. Ya no es un medio para un fin, como podía pasar en obras y autores anteriores. Ahora es el medio y es el fin. Es el todo y es la nada. Y volviendo al pensamiento de Cage, al rechazar la existencia de la obra misma como objeto, ya no es necesario un sujeto, no es necesario el autor como dictador de la verdad y ya no es necesario un intérprete para ejecutar esta verdad. El intérprete se emancipa de la superioridad estética del autor y se convierte en una figura autónoma e independiente en el proceso musical.

Llegados a este punto, es conveniente reflexionar sobre la relación del intérprete con su instrumento. Todo lo expuesto hasta ahora se ha centrado en las diferentes formas de afrontar el "texto musical" y de cómo los procesos compositivos de los autores han influido, directamente, en el rol y oficio del intérprete. Pero no hay que olvidar ni dejar de lado el vínculo que se crea entre el autor, el intérprete y el instrumento como un punto fundamental para entender cómo ha ido cambiando el propio oficio del performer.

Cuando uno piensa en música, es casi inevitable imaginar un instrumento que la realiza o reproduce. Entendemos el instrumento musical como algo necesario para crear música. También cuando nos referimos a la voz somos capaces de diferenciar la voz hablada de la cantada, que es utilizada como instrumento interno (y enseñada como tal en las instituciones de enseñanza musical, con el fin de aprender técnicas vocales interpretativas) (Nelson 1999, 70). Podríamos afirmar que el intérprete y su instrumento devienen una misma cosa, que tras años de estudio el ser humano ha conseguido adaptar a su cuerpo y su pensamiento esa "otra cosa", ese objeto, esa máquina. El intérprete se convierte en una especie de cíborg musical, si se me permite el paralelismo tecnológico. Más adelante veremos que este término cobra más sentido que nunca en la actualidad.

El aprendizaje de un instrumento musical es una tarea larga y compleja. Se requieren muchos años para "dominar" un instrumento en su totalidad. Anteriormente hablábamos de las dos principales funciones de la interpretación musical: hermenéutica y performativa. Podríamos traducir esos términos a funciones intelectuales y motrices, es decir, necesitamos entender para poder ejecutar. No existe un orden jerárquico en el que deban suceder ambas funciones, aunque el vínculo entre ellas es importante para poder llegar a interpretar un instrumento con fluidez y criterio, independientemente de si fue antes la teoría o la práctica. En definitiva, es todo un complejo proceso de aprendizaje del ser humano sobre el instrumento. El repertorio existente, tras siglos de creación musical, es muy extenso y demanda del ser humano un esfuerzo y trabajo muy especializados para poder interpretarlo de la manera en la que fue concebido. Es una continua "lucha" entre la perfección de lo escrito, de la idea, en contraposición con la imperfección humana. Por eso se necesita tanto tiempo para minimizar esa imperfección y poder acercarse a la idea musical. Este es, al menos, el planteamiento general desde las instituciones musicales y, en consecuencia, la organización de los estudios reglados de un instrumento musical.

Todas estas situaciones hacen que la relación de un intérprete con su instrumento sea muy íntima. Tantas horas, esfuerzo, sacrificio, alegrías y decepciones crean un vínculo casi inquebrantable. Un pianista no lo es sin un piano. Hoy en día, sin embargo, con los cambios tecnológicos y la revolución digital en el mundo del arte y de la música, esa relación está cambiando, ya que los propios instrumentos con los que interpretar están cambiando también. 


\section{EXTENDED PERFORMER}

\section{REDEFINICIÓN DEL INTÉRPRETE MUSICAL EN LA ACTUALIDAD}

Como hemos visto, los conceptos de obra, de autory de intérprete han sido ya cuestionados por otros compositores. Sin embargo, gracias a la llegada masiva de internet y de las nuevas tecnologías (y sus usos, como las redes sociales), todos estos conceptos, incluido el de público/oyente, urgen ser cuestionados de nuevo. Necesitan una redefinición. El formato mismo de concierto ya no tiene el mismo significado que antes. Ahora el medio es técnico (digital), no tiene por qué ser instrumental (entendido como instrumento acústico), el intérprete no tiene por qué haber seguido las líneas de aprendizaje tradicionales (entendidas como líneas de enseñanza de conservatorio o similares) y el público no tiene por qué estar en un mismo sitio para disfrutar de un concierto. Gracias a plataformas digitales como YouTube o Vimeo, pueden estar en el salón de su casa, en el metro o caminando por la calle mientras ven y escuchan la última obra que se está estrenando y emitiendo en streaming en el Festival de Darmstadt. Las nuevas tecnologías han redefinido la sociedad en la que vivimos, y como es lógico, en consecuencia, han redefinido también el arte y todas las figuras que forman parte del proceso creativo.

Extended performer es el término utilizado para hablar de un tipo de intérprete que está cada vez tomando más protagonismo en la escena contemporánea académica y experimental. Este auge es gracias a, en parte, la programación de festivales como Darmstädter Ferienkurse für Neue Musik, que, desde hace años, han sido generadores de tendencias compositivas y estéticas en el campo de la música contemporánea. El calificativo de extended nos remite directamente a las extended techniques (técnicas extendidas) que han caracterizado el cambio de paradigma en la técnica instrumental del siglo $X X$, es decir, todos aquellos sonidos no convencionales que podían descubrirse en un instrumento de tradición clásica. Igual que pasó en ese caso, es acertado utilizar ese mismo término para referirse al intérprete, ya que en muchos casos hasta el propio instrumento ha desaparecido y, en consecuencia, el intérprete, tal y como ha sido instruido, no tiene su función definida como en otras épocas y estilos.

Existe una clara tendencia entre algunos compositores a utilizar las nuevas tecnologías y los nuevos medios de difusión como soporte y como material compositivo. Hablamos de la digitalización de la música en el campo académico. ${ }^{1}$ Uno de sus mayores exponentes podría ser el compositor belga Stefan Prins. Su trabajo compositivo se centra en la utilización de medios digitales y gadgets, en el desarrollo musical de conceptos multimedia como los avatares y la expansión instrumental $-\mathrm{y}$, en consecuencia, expansión del intérprete- versus los instrumentos tradicionales. Buen ejemplo de ello podría ser Generation Kill (2012), obra que marca un punto de inflexión en la composición académica contemporánea de la última generación. Escrita para percusión, e-guitar, violín, violoncello, cuatro músicos con controladores de Playstation 3, live electronics y live video, la obra es una reflexión sobre diferentes conflictos bélicos que estaban sucediendo en esos años, como el conflicto en Irak o en Afganistán. Cito a continuación las palabras del propio autor para definir esta obra: 
Last year, while I was working on "Piano Hero \#1 and \#2", the Arab Revolutions had ignited the Middle-East. Protesters in several Middle-Eastern countries made the whole world witness the revolutionary events by making video's with their smartphones or webcams and uploading them to the internet. With the use of the social media — such as Facebook and Twitter- the whole process was accelerated, and before anyone realised, the people of Tunisia and Egypt had overthrown their dictatorial regimes, while full-blown civil wars started to split Libya and to paralyse Syria.

In the same year, 2011, a large-scale investigation was released, which calculated that there is one CCTV surveillance camera for every 32 persons in the UK.

October 2011: the Americans started to withdraw their troops in Iraq, while they were still fighting the taliban and Al Qaeda in Afghanistan. More and more images were released of successfull (at least according to the official bulletins) bombings by so-called "drones" - "unmanned aerial vehicles" who are remotely controlled by military personal in secret control centers in the US. Parallel to these images, an increasing stream of eye-witnesses started to appear on the internet, telling of innocent people who were killed by these bombings.

Strolling through the internet, I found at around the same time a 7-year old video-clip on YouTube which was a teaser for the TV-series "Generation Kill," based on the homonymous book in which Evan Wright chronicled his experiences as an embedded reporter with the 1st Reconnaissance Battalion of the US Marine Corps during the 2003 Iraq invasion. One of the statements which shocked me the most was made by one of the soldiers: "It's the ultimate rush - you're going into the fight with a good song playing in the background". Evan Wright explained further: "This is a war fought by the first playstation generation. One thing about them is they kill very well in Iraq."

At that point, I realised that my next piece had to musically reflect on all of these connected facts, on a society which is more and more monitored, on the increasing importance of internet, networks and social media, which are fuelled by video's taken with webcams and smartphones, on video-games and on wars fought like video-games, on the line between reality and virtuality which gets thinner by the day. ("Stefan Prins")

Como podemos comprobar, el autor se centra en problemas y herramientas coetáneos a su propia generación. Los músicos que manipulan el controlador de PS3 leen una partitura gestual y rítmica, que, a pesar de estar construida de forma musical (es decir, tiene en cuenta una estructura temporal), han de aprender a "tocar" un nuevo instrumento que nada tiene que ver con el propio. Lo que se debería considerar para ser un buen intérprete en una obra así, para definir este nuevo "virtuosismo", poco tiene que ver con la habilidad motriz o intelectual si lo comparamos con las habilidades para interpretar un instrumento tradicional. En algunos círculos, se le ha empezado a denominar cyborg virtuosity (Erwin 2016, 5). Los parámetros han cambiado. Son obras que apelan, directamente, a una generación, aquella que creció jugando a videojuegos y aprendió desde su infancia a usar un ordenador. Si uno en su juventud ha jugado con la PS3, conocerá mejor este instrumento que se usa en Generation Kill y, a priori, podrá interpretar mejor la obra. No importa si se es pianista, percusionista o cantante. 
Hemos podido observar ya que el instrumento tradicional, tal y como lo conocíamos, se ha convertido en una opción entre otras muchas. En este punto, cabría preguntarse ¿qué tipo de nueva relación se crea ahora entre el intérprete y su instrumento o máquina? Toda esta revolución tecnológica se lleva gestando desde hace años. Podríamos remontarnos a la musique concrete de Pierre Schaeffer para entender el principio del cambio de mentalidad. Las máquinas tienen desde entonces la capacidad de crear música. A partir de ahí, todo ha ido evolucionando rápidamente. Se crearon laboratorios de electrónica, y la música electoracústica y acusmática se convirtieron en género, con un sillón propio dentro de la academia. Sin embargo, esta música siempre se diferenció de la música instrumental. Por un lado, estaba la tradición, el instrumento acústico, la interacción humana; por otro, lo electrónico, la máquina, lo "no humano." Por supuesto, esta visión dualista ha ido desapareciendo a lo largo de los años. Hoy en día, son los mismos instrumentos los que son de origen electrónico o digital. Funcionan como herramientas, como medios, igual que lo han hecho siempre los instrumentos acústicos. Sin embargo, existen algunas diferencias sobre las que me gustaría reflexionar en lo referente a la naturaleza de estos nuevos instrumentos y la relación que, por consiguiente, se crea con el intérprete y el autor.

Uno de los motivos por los que la tecnología actual avanza rápidamente y está en constante evolución y mejora es porque estas "máquinas" están pensadas para hacernos la vida más fácil. Están, a grandes rasgos, diseñadas para ser accesibles al usuario. Las ventajas de esta concepción son muchas, principalmente, el mayor acceso a estas tecnologías por parte de la sociedad. Se diseñan e inventan nuevos aparatos y gadgets para que puedan satisfacer nuestras necesidades y realicen tareas que somos capaces de pensar e imaginar, pero no ejecutar. Haciendo el paralelismo con el intérprete musical, el ser humano tiene el conocimiento (hermenéutica) y la máquina ejecuta (performativo). Es decir, nos colocamos en una posición de poder, sometiendo la máquina a nuestros deseos (términos como Controlador MIDI son bastante sintomáticos de esta relación humano-tecnología). Autores como Edgar Varèse ya soñaban con disponer de este tipo de tecnología como herramienta para crear, y así lo expresó ya en 1917: "Sueño con instrumentos que obedezcan a mi pensamiento, y que con la ayuda de un sinfín de timbres inimaginables se presten a cualquier combinación que yo desee imponerles y se rindan a las exigencias de mi ritmo interno" (citado por Nelson 1999, 72).

El nivel de trabajo que se requiere por parte del intérprete para "dominar" estos nuevos instrumentos no es comparable al tiempo (cuantificable) que se requiere para saber interpretar correctamente, por ejemplo, una sonata de Beethoven. No obstante, queda claro que ambas opciones son reflejo de su época y, por consiguiente, formas igual de válidas de expresión y creación musical.

Si nos fijamos, sin embargo, en la relación del autor con estos nuevos instrumentos, veremos que es bastante diferente de la del intérprete. Para que un compositor sepa escribir para estos nuevos instrumentos, debe adquirir conocimientos que no tienen que estar relacionados con los musicales. Hablamos de conocimientos de informática, electrónica o programación. Para ellos sí que existe una dificultad añadida en la parte de la creación. Esta situación, en relación con el intérprete, no hace más que aumentar la distancia jerárquica que existe en la creación musical en la que, como ya he mencionado, el compositor estaría en lo más alto. Un intérprete no necesita saber cómo está programada una obra para interpretarla. No conoce el código interno. Su trabajo, más que nunca, se resume en ejecutar, no únicamente, pero el trabajo hermenéutico se reduce si lo comparamos con la música 
tradicional, en la que el trabajo de análisis de la partitura y de la comprensión de estructuras internas del texto es más evidente. Compositor e intérprete conocen el mismo lenguaje de ordenación de sonidos, ya que ambos han sido educados de la misma manera durante gran parte de su enseñanza musical. El autor no va a beneficiarse de los conocimientos del intérprete, como puede pasar con los instrumentos acústicos, en situaciones en las que colaboraciones entre intérprete y compositor hacen que surjan nuevos sonidos o técnicas desconocidas hasta el momento. Por supuesto, nadie impide que el intérprete tenga conocimientos de informática o programación y, de hecho, es algo por tener muy en cuenta ante la renovación del sistema educativo musical.

Otra corriente por considerar en esta nueva época de la música contemporánea es el Neuer Konzeptualismus. Podría definirse, a grandes rasgos, como una corriente de pensamiento compositiva que utiliza conceptos (estéticos, filosóficos, tecnológicos, sociales) como material generador compositivo, en vez de los sonidos (Erwin 2016, 5). A pesar de que dentro de lo considerado música conceptual actual existen diferentes subcategorías de compositores, la persona que más ha contribuido y teorizado al respecto es, sin duda, el compositor alemán Johannes Kreidler.

Kreidler se ha dado a conocer en el mundo de la música contemporánea a través de ciertas obras polémicas, muchas veces criticadas por los "grandes" del sector, como Helmut Lachenmann, quien señaló que la obra minusBolero, de Kreidler, no podía considerarse música y que no era más que una burla al oficio. Esta obra de Kreidler explora el concepto de memoria auditiva del público. Es una copia literal del Bolero de Ravel, pero sin la línea melódica. Según el autor, es una obra que tardó cinco años en pensar, y solo una hora en realizar ("minusBolero" 2015). La realización de la idea es muy simple, y plantea muchos debates posibles sobre el concepto de autoría y originalidad. Pero lo cierto es que, cuando uno escucha el minusBolero, la melodía del Bolero de Ravel aparece instantáneamente en la mente de cada persona del público, y es imposible de sacar hasta que no termina. El recorrido mental, la guía para la memoria auditiva del público, está magistralmente trazada y controlada por el autor. Podríamos entrar en muchos debates estéticos y éticos con esta obra, pero lo que no podemos negar es que el autor consigue lo que se propone a todos los niveles (teórico y práctico). Existen otras obras de Kreidler que han suscitado polémica en el mundo de la música contemporánea, como Fremdarbeit, obra que pone en duda la autoría de una obra de arte y todo el mercado que hay alrededor de los derechos de autor. Aquí el autor recibe un encargo para componer una obra para ensemble. Con el dinero de ese encargo, contrata a dos personas para que compongan esa obra: una en la India, que analiza digitalmente los patrones compositivos de las obras compuestas por Kreidler hasta la fecha (generación algorítmica), y otra en China que, con esos datos, compone una obra para ensemble que "suene como Kreidler". La explicación del proceso creativo la dio el propio autor después del estreno de la obra. Uno puede imaginarse que nadie se dio cuenta del "fraude". Sin embargo, tras la explicación, varias personas del público se sintieron defraudadas. Pero ¿existe realmente un fraude? ¿Es la obra el resultado musical del estreno, o lo es la idea de cómo realizar el proceso creativo de la obra como crítica al concepto mismo de autoría? (Kreidler 2009).

La finalidad última del Neuer Konzeptualismus es la emisión del mensaje de un concepto, independiente de si ese mensaje es emitido por intérpretes (como es el caso de minusBolero) o por máquinas. En este caso, el cambio, como ya pasó con Fluxus, remite más al marco teórico de la composición o del arte sonoro que a la puesta en práctica de la obra. 


\section{CONCLUSIONES}

Con esta pequeña muestra de lo expuesto, uno ya puede ver que la figura del intérprete, y lo que la interpretación musical es está en constante cambio debido a todas estas nuevas corrientes de vanguardia musical. Existe toda clase de factores por tener en cuenta para analizar la interpretación musical hoy en día, ya que todo, desde el formato hasta el resultado sonoro, pasando por el instrumento o el concepto mismo de idea musical, están cambiando. Muchas obras ya ni siquiera necesitan un intérprete, al disponer el autor de medios digitales para interpretarla. O incluso es el propio compositor el que interpreta sus propias obras (composer-performer), como el mismo Johannes Kreidler en Kinect Studies (obra audiovisual pensada directamente para plataformas digitales, como YouTube, en las que lo sonoro es accionado por sensores de movimiento) o la irlandesa Jennifer Walshe, quien, al ser ella misma cantante (con una técnica performativa muy particular), dirige gran parte de su corpus de obras a ella misma como intérprete.

El constante desarrollo de las nuevas tecnologías y de los instrumentos virtuales hace que nos replanteemos desde la creación y desde la interpretación el vínculo y el uso de estos nuevos instrumentos. El uso que estamos dando a estos instrumentos y la posición de control que adoptamos en relación con ellos abre toda una vía de preguntas y cuestiones con carácter no solo artístico sino también ético, estético y social.

Uno de los parámetros que no ha cambiado a lo largo de los años en lo referente a crítica y análisis estético en el arte es el de la originalidad. La obra de arte aspira a ser única, irrepetible, y de ahí su valor inmaterial e importancia histórica. Sin embargo, ese significado de unicidad ha cambiado desde el momento en el que los medios técnicos han evolucionado hasta el punto de que cualquier obra de arte es reproducible, duplicable. La obra de arte musical, sin embargo, que se preexiste guardada en la memoria del músico o en las notaciones de una partitura, pasa a existir realmente todas las veces que es ejecutada por uno de sus innumerables intérpretes. No hay de ella una performance original y auténtica que esté siendo copiada por todas las demás. Existe en infinitas versiones o actualizaciones diferentes y es, sin embrago, en cada caso siempre única. Su unicidad no es perenne y excluyente, sino reactualizable y convocante. Es siempre la misma y siempre otra. Es una obra de arte que está hecha para ser reproducida o que solo existe bajo el modo de la reproducción (Echeverría 2003, 16). En este aspecto, las máquinas están duplicando una parte del rol que el intérprete musical ha tenido a lo largo de la historia. El intérprete se convierte en una suerte de manipulador de sonidos que la máquina ha ejecutado y que ella previamente ya ha interpretado, a través de la programación del autor.

Definir la situación actual de la interpretación tiene la dificultad de ser abordada desde la contemporaneidad y la falta de distancia o perspectiva nos ponen la tarea aún más difícil. La función hermenéutica del intérprete ha cambiado y demanda una revisión en las instituciones musicales para poder comprender las nuevas necesidades de la interpretación musical. La clara delimitación de funciones que existía al principio de este artículo sobre el trabajo del intérprete termina con líneas difuminadas, si no borradas, que no dejan más que preguntas abiertas, pendientes de un más amplio análisis y reflexión. 


\section{NOTAS}

1. Hago la diferenciación del mundo académico, ya que en otros sectores de música electrónica más comercial o underground (y también experimental) ya se está hablando de la era posdigital.

\section{REFERENCIAS}

Cage, J. 1949 [2011]. Lecture on Nothing. Errant Bodies Records.

Cage, John. 1973. Silence. Hanover: Wesleyan University Press.

Danuser, Hermann. 2016. "Interpretación." Revista de Musicología 39 (1): 19-45. DOI: 10.2307/24878536.

Echeverría, Bolívar. 2003. Introducción a La obra de arte en la época de su reproductibilidad técnica, de Walter Benjamin, 9-28, México: Itaca.

Erwin, Max. 2016. "Here comes Newer Despair: An Aesthetic Primer for the New Conceptualism of Johannes Kreidler". Tempo 70 (278): 5-15. https://www.cambridge.org/core/journals/tempo/article/ here-comes-newer-despair-an-aesthetic-primer-for-the-new-conceptualism-of-johannes-kreidler/156 3136B03BB2DBD63CB264D12D6F572.

Fernández Guerra, Jorge. 1985. Pierre Boulez. Madrid: Círculo de Bellas Artes.

Fuhrmann, Wolfgang. 2011. "Toward a Theory of Socio-Musical Systems: Reflections on Niklas Luhmann's Challenge to Music Sociology". Acta Musicologica 83 (1): 135-159.

Gadamer, Hans-Georg. 1996. Estética y hermenéutica. Madrid:Tecnos.

Gottstein, Björn. 2011. “Digitalisierung und Musik / ein (Streit-) gespräch zwischen Claus-Steffen Mahnkopf und Johannes Kreidler ; moderiert von Björn Gottstein". Musik Texte Köln 128.

Hegel, Georg W. Friedrich. 1985. Estética: la pintura y la música. Buenos Aires: Siglo XXI.

“Interpretar". 2014. Diccionario de la lengua española. http://dle.rae.es/?id=LwUON38.

Kreidler, Johannes. 2009. "Fremdarbeit." https://www.youtube.com/watch?v=L72d_0zlT0c\&feature=youtu.be.

- 2011. Musik mit Musik: Texte 2005-2011. Múnich: Volke-Verlag.

Kreidler, Johannes, Harry Lehmann y Claus-Steffen Mahnkopf. 2010. Musik, Ästhetik, Digitalisierung: Eine Kontroverse. Hofheim: Wolke.

"minusBolero". 2015. Kreidler-net. http://www.kreidler-net.de/theorie/minusbolero.pdf.

Nelson, Peter. 1999. “El cyborg musical". En Música y nuevas tecnologías: perspectivas para el siglo XXI, de Eduardo Reck Miranda, 69-83. Barcelona: L'Angelot.

Pardo Salgado, Carmen. 1999. “Interpret/acción". Contrastes: Revista Internacional de Filosofía 4: 135-148.

DOI: http://dx.doi.org/10.24310/Contrastescontrastes.v0i0.1508

- 2014. La escucha oblicua: una invitación a John Cage. Madrid: Ensayo Sexto Piso.

Rivière Ríos, Henar. 2011. "Papeles para la historia de Fluxus y Zaj: entre el documento y la práctica artística". Anales de Historia del Arte, Volumen Extraordinario: 421-436.

"Stefan Prins". 2012. Stefanprins.be. http://www.stefanprins.be/eng/composesChrono/comp_2012_03.html

Stravinsky, Igor. 2006. Poética musical. Barcelona: Acantilado. 